\title{
Phase variation in tcpH modulates expression of the Tox $R$ regulon in Vibrio cholerae
}

Patricia A. Carroll, ${ }^{1 \ddagger}$ Karen T. Tashima, ${ }^{1 \dagger \ddagger}$ Marc B. Rogers, ${ }^{1}$ Victor J. DiRita ${ }^{2,3}$ and Stephen B. Calderwood ${ }^{1,4} *$

${ }^{1}$ Infectious Disease Division, Massachusetts General Hospital, Boston, MA 02114, USA.

${ }^{2}$ Department of Microbiology and Immunology, University of Michigan Medical School, Ann Arbor, MI 48109, USA.

${ }^{3}$ Unit for Laboratory Animal Medicine, University of Michigan Medical School, Ann Arbor, MI 48109, USA. ${ }^{4}$ Department of Microbiology and Molecular Genetics, Harvard Medical School, Boston, MA 02115, USA.

\section{Summary}

We evaluated a spontaneous mutant of Vibrio cholerae, which was avirulent in an infant mouse and had reduced expression of cholera toxin and TcpA in response to environmental signals. The tox $R$, toxS and toxT genes in the mutant were normal, but transcription of toxT was absent. A plasmid expressing wild-type tcpP and $t c p H$ complemented the mutant. The mutation resulted from a frameshift in a string of nine G residues within $t c p H$; similar slipped-strand mutations in $\mathrm{tcpH}$ arose at a frequency of $10^{-4}$ during overnight growth and in the majority of colonies by the end of 5 days of growth in ToxR-inducing conditions. Transcription of $t c p P H$ was regulated by temperature and $\mathrm{pH}$ independently of ToxR or ToxT. These results suggest that TcpH couples environmental signals (temperature and $\mathrm{pH}$ ) to expression of the ToxR regulon, and provide a model for phase variation in the co-ordinate expression of cholera virulence factors.

\section{Introduction}

The bacterium Vibrio cholerae causes epidemics of a severe secretory diarrhoea in developing countries. The best-studied virulence factor of this organism is cholera toxin, a protein composed of a single $A$ subunit and five identical B subunits. The B pentamer of cholera toxin

Received 19 May, 1997; revised 14 July, 1997; accepted 15 July, 1997. †Present address: Miriam Hospital, 164 Summit Avenue, Providence, RI 02906, USA. ¥These authors contributed equally to this study. *For correspondence: Infectious Disease Division, Massachusetts General Hospital, Boston, MA 02114, USA. E-mail calderwood stephen@mgh.harvard.edu; Tel. (617) 726 3811; Fax (617) 726 7416.

(C) 1997 Blackwell Science Ltd binds to $\mathrm{GM}_{1}$ ganglioside on the host cell surface. The enzymatically active $A$ subunit is proteolytically nicked, reduced to $A_{1}$ and $A_{2}$ fragments and enters the cytosol to activate adenylate cyclase, leading to elevation of cAMP and secretion of chloride and water. The expression of cholera toxin by $V$. cholerae is not constitutive in vitro, but is activated by selected environmental conditions, including $\mathrm{pH}$, temperature and osmolarity, which may mimic in vivo regulatory signals (Miller and Mekalanos, 1988).

A second important virulence factor for $V$. cholerae is the toxin co-regulated pilus (Tcp) (Taylor et al., 1987), an adhesin whose expression is regulated in response to environmental signals in a similar manner to cholera toxin. Tcp is essential for colonization and virulence in both animal models and human volunteer studies (Taylor et al., 1987; Herrington et al., 1988). The major structural gene of the pilus, tcp $A$, is part of a larger gene cluster, encoding additional proteins involved in pilus assembly and transport (Ogierman and Manning, 1992; Kaufman et al., 1993).

ToxR, a transmembrane protein homologous to the twocomponent class of transcriptional regulators, is necessary for activating many genes in $V$. cholerae, including the cholera toxin and tcp operons and the gene encoding an outer membrane protein, OmpU (Miller and Mekalanos, 1984; Miller et al., 1987; Taylor et al., 1987). toxS is transcribed in an operon with tox $R$ and is proposed to assist ToxR function, perhaps by stabilizing a ToxR dimer (Miller et al., 1989; DiRita and Mekalanos, 1991). ToxR binds to a repeated DNA sequence, TTTTGAT, present in three to eight copies upstream of the cholera toxin promoter (Miller et al., 1987), and directly activates ctx transcription in Escherichia coli (Miller and Mekalanos, 1984). However, ToxR does not activate $t c p A$ transcription directly, but rather activates transcription of a gene encoding another transcriptional activator, toxT (DiRita et al., 1991).

ToxT has been identified as a protein that activates a ctx::lacZ fusion in E. coli, as well as fusions of lacZ to several genes in the tcp gene cluster, including $t c p A$ (DiRita et al., 1991). ToxT is a member of the AraC family of transcriptional activators (Higgins et al., 1992; Ogierman and Manning, 1992). Expression of tox $T$ is modulated by the same environmental growth conditions as expression of cholera toxin and Tcp; expression of tox $T$ is also dramatically reduced in the presence of a tox $R$ mutation. Expression of tox $T$ from a constitutive promoter partially corrects a tox $R$ mutant phenotype (except for the expression of 
OmpU), consistent with a position for ToxT downstream of ToxR in a regulatory cascade (DiRita et al., 1991). In this cascade, ToxR activates transcription of cholera toxin, OmpU and tox $T$, and ToxT in turn activates transcription of the other virulence genes of $V$. cholerae (DiRita, 1992). Since expression of Tox $R$ is not itself regulated by environmental conditions that modulate expression of cholera toxin and Tcp (DiRita, 1992), the mechanism by which these conditions modulate expression of genes in the ToxR regulon is not well understood.

The gene encoding ToxT is located within the tcp gene cluster, between tcpF and tcpJ (Higgins et al., 1992; Kaufman et al., 1993; Ogierman et al., 1993). Just downstream of the gene for $t c p F$, there is a relatively strong transcriptional terminator (approximately $80 \%$ effective) (Higgins and DiRita, 1994). Two primer extension products for toxT have been mapped, one of which is ToxR dependent and the other ToxR independent. ToxR binds to a fragment of DNA upstream of toxT and containing the ToxRdependent promoter, suggesting direct involvement of ToxR in the expression of toxT. However, ToxR is not sufficient in $E$. coli to activate a toxT::lacZ fusion and, in fact, represses expression from the tox $T$ promoter, suggesting the possibility that expression of toxT requires factors in addition to ToxR (Higgins and DiRita, 1994).

RNase protection experiments have demonstrated transcripts containing tcpA by itself, as well as transcripts including all of the genes downstream in the tcp operon, including tcpF, toxT and tcpJ (Brown and Taylor, 1995). Polar mutations in the tcp operon upstream of tox $T$ decrease the expression of $\operatorname{tcp} A$ and $\operatorname{ct} x A B$, most probably via an effect on the expression of toxT downstream. This suggests a model in which there is a basal level of tox $T$ expression that is independent of ToxR. Under ToxR-inducing environmental conditions, there is enhanced expression of toxT at the ToxR-dependent promoter, activation of the $\operatorname{tcp} A$ promoter by ToxT and positive autoregulation of toxT in a transcript originating at the upstream tcpA promoter (Brown and Taylor, 1995).

Taylor et al. (1988) have previously used TnphoA mutagenesis to identify genes in $V$. cholerae that are ToxR regulated and affect autoagglutination (a phenotype correlated with production of $\mathrm{Tcp}$ ). In addition to genes in the tcp $A$ operon, these studies disclosed two genes upstream of $t c p A, t c p H$ (transcribed in the same direction as $t c p A$ ) and $t c p l$ (divergently transcribed); the phenotypes of mutations in these genes suggested that $\mathrm{TcpH}$ was a positive regulator of the $t c p A$ operon and Tcpl was a negative regulator. Ogierman et al. (1993) subsequently described an additional gene, $t c p P$, located between $t c p /$ and $t c p H$ and transcribed in the same direction as $t c p H$.

We have previously studied the role of genes in $V$. cholerae that are repressed in the presence of iron and important to virulence (Goldberg et al., 1990a; 1990b;
1991). We were interested in finding whether any virulence factors of $V$. cholerae were activated rather than repressed in the presence of iron. In the course of these studies, we isolated a TnphoA mutant of classical $V$. cholerae $\mathrm{O} 1$ in a gene that was positively regulated in response to environmental iron. This strain was entirely avirulent in an animal model. The mutation in the strain, however, was independent of the TnphoA insertion and arose spontaneously during construction of the strain. Characterization of this mutant revealed that it was defective in the transcription of toxT, could be complemented by a plasmid expressing $t c p P H$ in trans and contained a slipped-strand mutation in a string of $G$ residues within the open reading frame of $t c p H$, resulting in a frameshift. Slipped-strand mutations in the polyguanine tract in $t c p H$ occurred spontaneously at a frequency of approximately $10^{-4}$ after overnight growth, and accumulated in the majority of colonies after 5 days of growth in ToxR-inducing conditions. We propose that slipped-strand mutations in $t c p H$ represent a mechanism for phase variation in the expression of the Tox $R$ regulon and could play a role in the natural infectious cycle.

\section{Results}

Identification of $\mathrm{V}$. cholerae mutant strains containing TnphoA inserted in genes positively regulated by iron

After random mutagenesis of the chromosome of $V$. cholerae $\mathrm{O} 395$ with TnphoA, colonies were screened for the $\mathrm{PhoA}^{+}$phenotype by blue colour on a plate containing 5-bromo-4-chloro-3-indolyl phosphate (XP). Alkaline phosphatase assays were performed on 77 active TnphoA fusion strains under low- and high-iron conditions, yielding five strains with increased alkaline phosphatase activities in high-iron compared with low-iron conditions (induction ratios ranging from 2.9 to 4.5 ).

\section{Virulence assays}

Four of the five strains containing TnphoA fusions positively regulated by iron were screened for loss of virulence in the infant mouse model, using two mice per strain and a dose more than 50 times the $\mathrm{LD}_{50}$ of the wild type. One strain, KTT42, failed to kill the mice in this screening and was entirely avirulent on more thorough testing $\left(L D_{50}\right.$ of $>6 \times 10^{9}$ compared with $1 \times 10^{6}$ for the wild type). In in vivo competition assays, co-infection of mice with KTT42 and 0395 revealed a competitive index of 0.05 , or a roughly 20 -fold reduction in colonization by the mutant. The in vitro competitive index of 1.1 suggested against an in vitro growth defect in the mutant strain.

\section{Lack of autoagglutination and reduced expression of TcpA and cholera toxin by KTT42}

Overnight growth of wild-type $\mathrm{O} 395$ in ToxR-inducing 
environmental conditions causes visible clumping of bacteria, leaving a pellet at the bottom of the tube and a clear supernatant (not shown). This property of autoagglutination has previously been shown to correlate with the expression of Tcp (Taylor et al., 1987). KTT42 failed to demonstrate autoagglutination under similar conditions. Expression of both TcpA and cholera toxin was substantially decreased in KTT42 compared with 0395, but remained responsive to ToxR-modulating environmental conditions (Fig. 1, lanes 1-4).

\section{The TnphoA insertion in KTT42 is not responsible} for the mutant phenotypes

Southern hybridization of EcoRV-digested chromosomal DNA confirmed a single TnphoA insertion in strain KTT42 (not shown). The TnphoA insertion in KTT42 was replaced by wild-type chromosomal DNA from 0395 using marker exchange with pPAC7 to create strain KTT7-1. Although we had expected that the reverted strain would have a wild-type phenotype, KTT7-1 failed to autoagglutinate and produced only $236 \mathrm{ng} \mathrm{ml}^{-1} / \mathrm{OD}_{600}$ units of cholera toxin under ToxR-inducing conditions. In the same assay, KTT42 produced $284 \mathrm{ng} \mathrm{ml}^{-1} / \mathrm{OD}_{600}$ units, suggesting that the somewhat higher level of cholera toxin seen with both strains in this assay compared with others was caused by experimental variability. A virulence assay with KTT7-1 demonstrated the same virulence defect as KTT42 (not shown). We conclude that the TnphoA insertion in KTT42 is not responsible for the mutant phenotypes of this strain, but that a second mutation arose during isolation of KTT42.

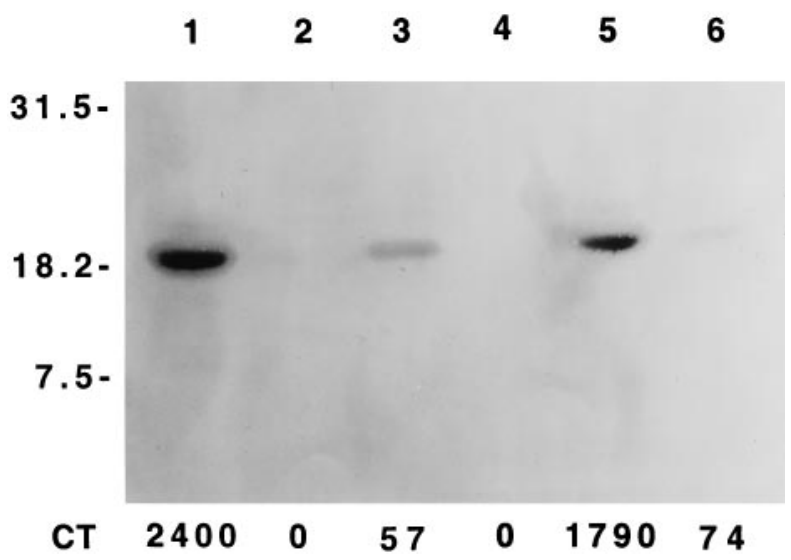

Fig. 1. Western immunoblot of TcpA and measurement of cholera toxin in supernatants of various strains following growth in ToxR-inducing or ToxR-repressing conditions. Lanes: 1 and 2, O395 ToxR-inducing and ToxR-repressing conditions respectively; 3 and 4, KTT42 in ToxR-inducing and ToxR-repressing conditions respectively; 5 and 6 , KTT42 (pPAC25) in ToxR-inducing and ToxR-repressing conditions respectively. Numbers at left identify positions of molecular weight markers $(\mathrm{kDa})$. Numbers at bottom express cholera toxin measurements in supernatants (ng ml $^{-1} / \mathrm{OD}_{600}$ of culture).
123456

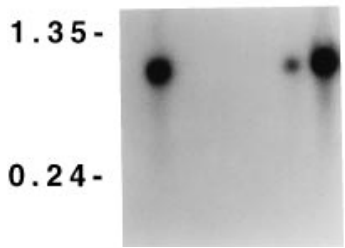

Fig. 2. Northern blot of $\operatorname{tcp} A$ message produced by various strains following growth in ToxR-inducing or ToxR-repressing conditions. Lanes: 1 and 2, 0395 in ToxR-inducing and ToxR-repressing conditions respectively; 3, JJM43 (O395-N1 toxR) in ToxR-inducing conditions; 4, VJ675 (O395 toxT) in ToxR-inducing conditions; 5, KTT42 in ToxR-inducing conditions; 6, KTT42 (pMT5) in ToxR-inducing conditions. Numbers at left identify positions of molecular weight markers $(\mathrm{kb})$.

\section{KTT42 has a regulatory rather than a secretory defect}

To examine the possibility that KTT42 has a defect in secretion of virulence products, as described in eps mutants (Sandvist et al., 1993), cholera toxin assays were performed on whole-cell and periplasmic extracts under ToxR-inducing conditions. Strain 0395 contained $19 \mathrm{ng} \mathrm{ml}^{-1} / \mathrm{OD}_{600}$ units of cholera toxin by enzyme-linked immunosorbent assay (ELISA) in a whole-cell extract compared with $2.1 \mathrm{ng} \mathrm{ml}^{-1}$ / $\mathrm{OD}_{600}$ units for strain KTT42. Periplasmic extracts of 0395 and KTT42 contained $3.3 \mathrm{ng} \mathrm{ml}^{-1} / \mathrm{OD}_{600}$ and $<0.1 \mathrm{ng} \mathrm{ml}^{-1} / \mathrm{OD}_{600}$ units of cholera toxin respectively. Secretion of haemagglutinin-protease, a protein secreted by the same Eps system that is responsible for cholera toxin secretion but is not in the ToxR regulon, was similar in 0395 and KTT42 (not shown). Northern blot analysis of tcpA message in KTT42 under ToxR-inducing conditions (Fig. 2, lane 5) showed that tcpA transcription was reduced compared with $\mathrm{O} 395$ (Fig. 2, lane 1); no tcpA transcript was seen for either strain under ToxR-repressing conditions, or in toxR or tox $T$ mutant strains (Fig. 2, lanes 3 and 4$)$. These results suggest a regulatory rather than a secretory defect in KTT42.

\section{Analysis of toxR, toxS and toxT in KTT42}

We compared the phenotypes of KTT42 with strains of O395 mutant in toxR or tox $T$, as well as the effects of plasmids expressing wild-type toxRS or tox $T$ for complementation (Table 1). The toxR mutant, JJM43, was markedly reduced in cholera toxin production, failed to autoagglutinate or produce TcpA and had reversal of the wild-type pattern of OmpU/OmpT; each of these mutant phenotypes was restored by PKTT5 in trans. As observed before (DiRita et al., 1996), cholera toxin production, autoagglutination and production of TcpA were also restored by pMT5 in trans, consistent with the position of tox $T$ at the end of a regulatory cascade, but PMT5 did not restore the wild-type 
Table 1. Phenotypes of $\mathrm{O} 395$ and various mutants, with or without plasmids expressing toxRS or toxT, following growth in ToxR-inducing conditions.

\begin{tabular}{|c|c|c|c|c|c|}
\hline Strain & $\begin{array}{l}\text { Production of } \\
\text { cholera toxin }^{a}\end{array}$ & Autoagglutination & $\begin{array}{l}\text { Production } \\
\text { of TcpA }\end{array}$ & $\begin{array}{l}\text { Production } \\
\text { of OmpU }\end{array}$ & $\begin{array}{l}\text { Production } \\
\text { of OmpT }\end{array}$ \\
\hline 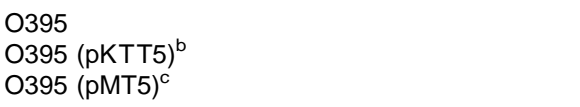 & $\begin{array}{l}2600 \\
5455 \\
5000\end{array}$ & $\begin{array}{l}+ \\
+ \\
+\end{array}$ & $\begin{array}{l}+ \\
+ \\
+\end{array}$ & $\begin{array}{l}\text { Yes } \\
\text { Yes } \\
\text { Yes }\end{array}$ & $\begin{array}{l}\text { No } \\
\text { No } \\
\text { No }\end{array}$ \\
\hline $\begin{array}{l}\text { JJM43 } \\
\text { JJM43 (pKTT5) } \\
\text { JJM43 (pMT5) }\end{array}$ & $\begin{array}{r}<1 \\
1347 \\
6300\end{array}$ & $\begin{array}{l}- \\
+ \\
+\end{array}$ & $\begin{array}{l}- \\
+ \\
+\end{array}$ & $\begin{array}{l}\text { No } \\
\text { Yes } \\
\text { No }\end{array}$ & $\begin{array}{l}\text { Yes } \\
\text { No } \\
\text { Yes }\end{array}$ \\
\hline $\begin{array}{l}\text { VJ675 } \\
\text { VJ675 (pKTT5) } \\
\text { VJ675 (pMT5) }\end{array}$ & $\begin{array}{r}<1 \\
<1 \\
3860\end{array}$ & $\begin{array}{l}- \\
- \\
+\end{array}$ & $\begin{array}{l}- \\
- \\
+\end{array}$ & $\begin{array}{l}\text { Yes } \\
\text { Yes } \\
\text { Yes }\end{array}$ & $\begin{array}{l}\text { No } \\
\text { No } \\
\text { No }\end{array}$ \\
\hline $\begin{array}{l}\text { KTT42 } \\
\text { KTT42 (pKTT5) } \\
\text { KTT42 (pMT5) }\end{array}$ & $\begin{array}{r}114 \\
25 \\
6500\end{array}$ & $\begin{array}{l}- \\
- \\
+\end{array}$ & $\begin{array}{l}- \\
- \\
+\end{array}$ & $\begin{array}{l}\text { Yes } \\
\text { Yes } \\
\text { Yes }\end{array}$ & $\begin{array}{l}\text { No } \\
\text { No } \\
\text { No }\end{array}$ \\
\hline $\begin{array}{l}\text { VJ675 (pLAFR3) } \\
\text { VJ675 (pPAC12; toxT gene cloned from O395) } \\
\text { VJ675 (pPAC15; toxT gene cloned from KTT42) }\end{array}$ & $\begin{array}{r}<1 \\
2709 \\
1061\end{array}$ & $\begin{array}{l}- \\
+ \\
+\end{array}$ & $\begin{array}{l}- \\
+ \\
+\end{array}$ & $\begin{array}{l}\text { Yes } \\
\text { Yes } \\
\text { Yes }\end{array}$ & $\begin{array}{l}\text { No } \\
\text { No } \\
\text { No }\end{array}$ \\
\hline
\end{tabular}

a. $\mathrm{ng} \mathrm{ml}^{-1} / \mathrm{OD}_{600}$ of culture.

b. pKTT5 expresses wild-type toxRS.

c. pMT5 expresses wild-type toxT from a tac promoter, which is induced by the addition of IPTG.

d. JJM43 is O395-N1 toxR.

e. VJ675 is 0395 toxT.

pattern of OmpU/OmpT. The toxT mutant, VJ675, had absent expression of cholera toxin, autoagglutination and TcpA, but a normal pattern of OmpU and OmpT; production of cholera toxin and TcpA were restored by pMT5, but not pKTT5.

Strain KTT42 was deficient for high-level cholera toxin and TcpA production, but expressed the wild-type pattern of OmpU and OmpT (Table 1). This phenotype was similar to that of the toxT null mutant, VJ675, although cholera toxin production in KTT42 was higher than was observed in the toxT mutant. A plasmid expressing toxRS in trans did not correct the mutant phenotypes of KTT42. ToxR protein in KTT42 was normal in both ToxR-inducing and ToxR-repressing conditions, and a Northern blot of RNA from KTT42 with a toxRS probe gave identical results to strain 0395 (not shown). There was no difference in the amount of toxRS message or ToxR protein in either strain, comparing ToxR-inducing with ToxR-repressing conditions, suggesting that environmental regulation of the ToxR regulon occurs at a step beyond the translation of ToxR. Plasmid pMT5 completely restored the mutant phenotypes of KTT42 (Table 1 and Fig. 2, lane 6), suggesting that this strain is mutant in toxT or in the expression of toxT.

To assess the ability of the toxT gene in KTT42 to function in complementation, plasmid pPAC15, encoding tox $T$ and upstream sequences from KTT42, was introduced into VJ675 and results compared with the toxT gene cloned from $\mathrm{O} 395$ on pPAC12 (Table 1); both toxT alleles complemented VJ675 similarly. The toxT alleles from 0395 and KTT42 were also sequenced from the polymerase chain reaction (PCR) products, starting at bp 1070 within the $t c p F$ gene upstream of the toxT promoter (Higgins and DiRita, 1994) and extending to bp 2132 downstream of the stop codon in toxT. Both sequences differed in one nucleotide from the published sequence of tox $T$ from strain 569B (Higgins et al., 1992), a G to a T at bp 1478, resulting in an alanine to serine substitution, but results were identical between strain 0395 and KTT42 (not shown). This same sequence change was found in toxT from another $V$. cholerae strain reported by Ogierman and Manning (1992). Sequence results for KTT42 were confirmed on two independent PCR products. We conclude that strain KTT42 has a wild-type toxT structural gene and promoter region, both by DNA sequence and by functionality, suggesting that the mutant phenotypes of KTT42 reflect reduced expression of toxT rather than a mutation in toxT itself.

\section{Transcription of toxT is reduced in KTT42}

We compared expression of toxT in KTT42 and 0395 by Northern blot, using RNA isolated after growth in ToxRinducing conditions; KTT42 failed to produce a detectable tox $T$-specific message (not shown). Primer extension of RNA from 0395 and KTT42 using a toxT-specific primer also showed that KTT42 had severely reduced amounts of both primer extension products seen with RNA from O395 (Fig. 3), confirming a defect in transcription of toxT.

(C) 1997 Blackwell Science Ltd, Molecular Microbiology, 25, 1099-1111 


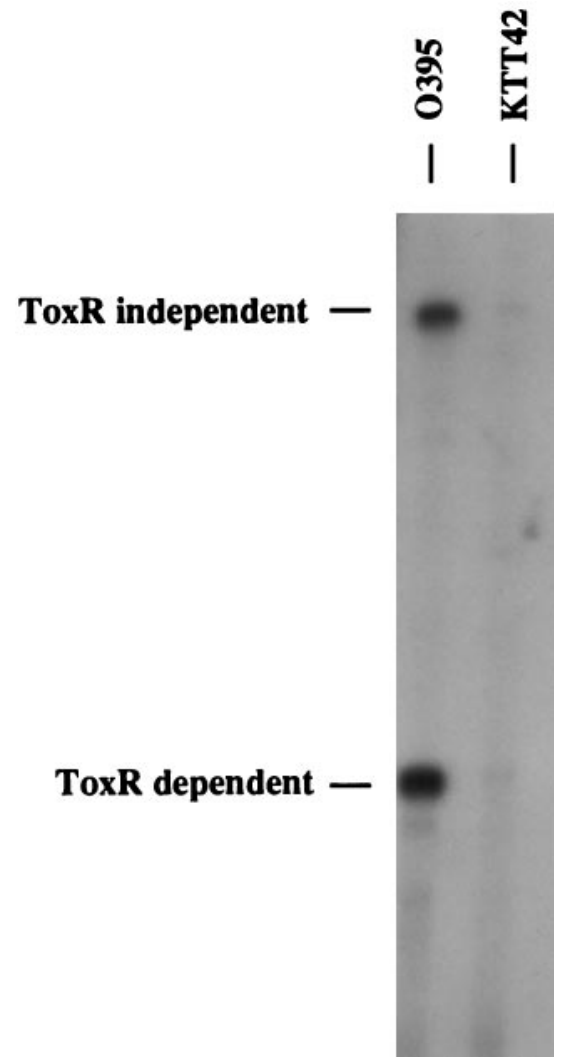

Fig. 3. Primer extension of RNA isolated from cultures of $\mathrm{O} 395$ and KTT42. The positions in the gel of the ToxR-dependent and -independent primer extension products of tox $T$, as defined in Higgins and DiRita (1994), are shown.

The phenotypes of strain KTT42 are complemented by tcpPH

Plasmid pCS2-1 contains a fragment of the $V$. cholerae chromosome encompassing DNA upstream and at the $5^{\prime}$ end of the $t c p A$ operon, with TnphoA inserted inframe within tcpA (Fig. 4). We decided to recover the Xbal fragment of pCS2-1, containing the tcpA::TnphoA fusion, and insert this within the lacZ locus of KTT7-1 to construct a derivative of this mutant containing a reporter activity to one of the promoters (tcpA) whose transcription was defective in the mutant. Although we intended to use this reporter strain to recover a complementing fragment of $V$. cholerae DNA from a chromosomal library that restored normal expression to the tcpA promoter, we found that the reporter strain itself, PAC29, had fully reverted the mutant phenotypes of strain KTT7-1 (Table 2). This suggested that one or more of the genes contained in the Xbal fragment of pCS2-1 was able to complement the mutation in trans.

To confirm this further, we used a previously constructed cosmid, pCS8C8, which contains V. cholerae O395 chromosomal DNA upstream of and at the $5^{\prime}$ end of the tcpA operon (Fig. 4), and showed that this complemented the

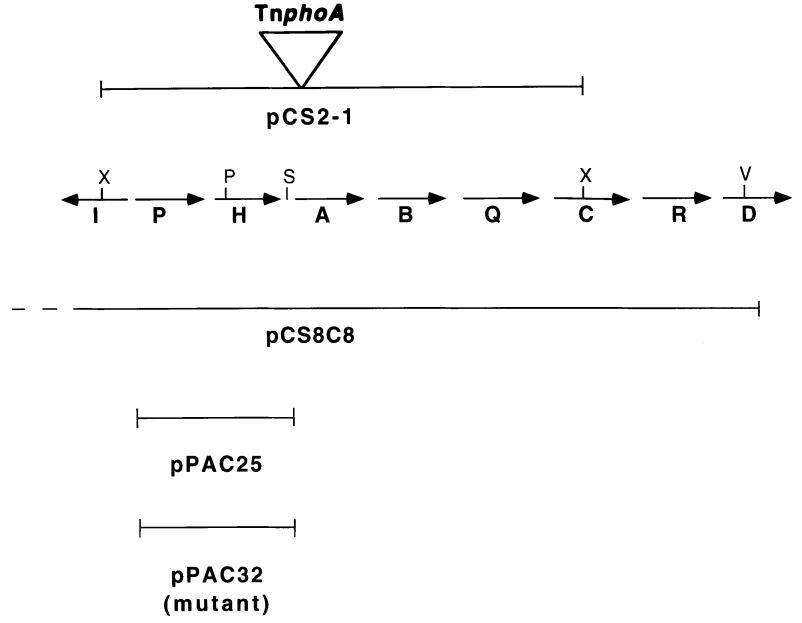

Fig. 4. Partial restriction map of $V$. cholerae $\mathrm{O} 395$ chromosomal DNA, upstream of and at the $5^{\prime}$ end of the tcpA operon, showing sequences contained in various plasmids used for complementation studies. X, Xbal; P, Pstl; S, Sphl; V, EcoRV.

phenotypic defects of KTT42 (Table 2). Plasmid pPAC25, expressing wild-type $t c p P H$ from its own promoter on a low-copy vector, complemented the mutant phenotypes of KTT42, while pPAC32, expressing tcpPH from the mutant itself, did not (Table 2). Plasmid pPAC25 also restored normal expression of TcpA by Western blot to the mutant (Fig. 1, lanes 5 and 6 ). These results suggested that the mutation in KTT42 was in tcpPH and could be complemented in trans.

\section{Transcription of tcpPH in KTT42 is normal}

Northern blot analysis of RNA, using a fragment probe encompassing both $t c p P$ and $t c p H$, demonstrated a single $t c p P H$ transcript that was strictly regulated in strain $\mathrm{O} 395$ in response to temperature and $\mathrm{pH}$ (Fig. 5, lanes 1 and 2).

Table 2. Complementation studies of $V$. cholerae KTT42 and KTT7-1 with various fragments of chromosomal DNA.

\begin{tabular}{lcc}
\hline Strain & Autoagglutination & $\begin{array}{c}\text { Production of } \\
\text { cholera toxin }^{\text {a }}\end{array}$ \\
\hline O395 & + & 2144 \\
KTT42 & - & 10 \\
KTT7-1 (KTT42 with TnphoA & - & 19 \\
$\quad$ insertion removed by & & \\
$\quad$ marker exchange with wild- & & \\
$\quad$ type DNA) & & \\
PAC29 (KTT7-1 lacZ::tcpl-C, & + & 2763 \\
$\quad$ tcpA ::TnphoA) & & 2485 \\
KTT42 (pCS8C8) & + & 9578 \\
KTT42 (pPAC25; expressing & + & \\
$\quad$ wild-type tcpPH) & - & 29 \\
KTT42 (pPAC32; expressing & & \\
$\quad$ tcpPH from KTT42) & & \\
\hline
\end{tabular}

a. $\mathrm{ng} \mathrm{ml}^{-1} / \mathrm{OD}_{600}$ of culture. 


\section{$\begin{array}{llllll}1 & 2 & 3 & 4 & 5 & 6\end{array}$}

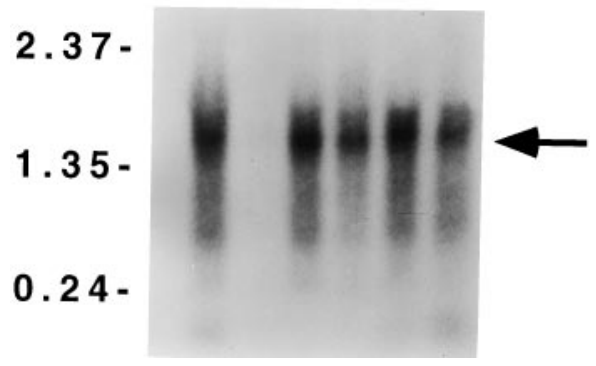

Fig. 5. Northern blot of RNA prepared from various $V$. cholerae strains and probed with a fragment containing tcpPH. Lanes: 1 and 2, O395 in ToxR-inducing and -repressing conditions respectively; 3, JJM43 (O395-N1 toxR) in ToxR-inducing conditions; 4, VJ675 (O395 toxT) in ToxR-inducing conditions; 5, KTT42 in ToxR-inducing conditions; 6, KTT42 (pMT5) in ToxR-inducing conditions. A single band is seen at the size predicted for a transcript including both $t c p P$ and $t c p H$. Numbers at the left identify positions of molecular weight markers (kb).

Expression of the $t c p P H$ transcript was at wild-type levels in tox $R$ and tox $T$ mutants (Fig. 5, lanes 3 and 4), suggesting that transcription of $t c p P H$ is regulated by temperature and $\mathrm{pH}$ independently of ToxR or ToxT. Transcription of $t c p P H$ was also at the wild-type level in the mutant KTT42, as well as KTT42 complemented with pMT5 (Fig. 5, lanes 5 and 6). The same results were obtained on Northern blots hybridized with PCR-generated fragments internal to $t c p P$ and $t c p H$ separately (not shown). This suggested that the mutation in KTT42 did not affect transcription of tcpPH but might be in the coding sequence itself.

\section{Strain KTT42 contains a frameshift mutation in tcpH}

The sequence of $t c p P H$ recovered by PCR from KTT42 was determined in duplicate and compared with the corresponding sequence from 0395 . The only difference between the two sequences was the addition in strain KTT42 of an extra $G$ residue in a string of nine $G$ residues at the amino terminus of the open reading frame of $t c p H$ (Fig. 6). Both sequences shared a difference from that recently reported in a classical strain of $V$. cholerae 01 by Ogierman et al. (1996); we did not find the T residue previously reported at bp 2756 , and this results in a different deduced carboxy terminus of TcpH (Fig. 6). Because pPAC25 but not pPAC32 complemented the mutant phenotypes of KTT42, and these plasmids differ only in the string of $\mathrm{G}$ residues in $t c p H$, we conclude that the mutation in KTT42 is limited to $t c p H$ and results from a slipped-strand mutation and frameshift.

\section{Frameshift mutations in tcpH occur at a frequency of $10^{-4}$ after overnight growth}

V. cholerae strain CS7-1 is a previously constructed derivative of strain $O 395$ (Shaw et al., 1990), containing an inframe fusion between $t c p H$ and TnphoA (Fig. 6). If mutation of $t c p H$ is responsible for the mutant phenotypes of strain KTT42, then strain CS7-1 would be expected to have similar alterations in phenotype. As shown in Table 3 , cholera toxin production by strain CS7-1 is indeed reduced to a level similar to that of KTT42. The alkaline phosphatase activity of the $t c p H:: T n p h o A$ fusion in CS7-1 also provides another means of quantitating expression from the $t c p P H$ promoter. As shown in Table 3, expression from this promoter was regulated in response to temperature and $\mathrm{pH}$ independently of toxR, consistent with the results of the tcpPH Northern blot for strains 0395 and JJM43 (Fig. 5).

CS7-1 gives a blue colony phenotype on XP-containing media, as a result of the in-frame fusion between the

\footnotetext{
$\begin{array}{llllllllllllllllllll}\text { L } & M & \text { F } & \text { A } & \text { I } & \text { D } & Q & \text { H } & Q & \text { C } & \text { S } & \text { V } & \text { N } & \text { Y } & \text { E } & Q & \text { K }\end{array}$ A CTC ATG TTC GCT ATT GAT CAA CAT CAG TGT TCC GTG AAT TAT GAA CAG AAG $\begin{array}{lllllllllllllllllll}T & \mathrm{~L} & \mathrm{E} & \mathrm{C} & \mathrm{T} & \mathrm{K} & \mathrm{N} & \bullet\end{array}$

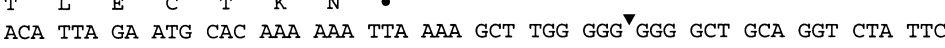
$\begin{array}{lllllllllllllllll}M & H & \text { K } & \text { K } & \text { L } & \text { K } & \text { A } & \text { W } & \text { G } & \text { G } & \text { A } & \text { A } & \text { G } & \text { L } & \text { F }\end{array}$

Fig. 6. DNA and deduced protein sequences at the $3^{\prime}$ end of $t c p P$ and all of $t c p H$ from $V$. cholerae 0395 . The nucleotide numbering corresponds to GenBank accession number $2415 \mathrm{X} 64098$. The deduced protein sequence of the carboxy terminus of TcpP is shown above the corresponding nucleotides and that of $\mathrm{TcpH}$ is shown below; the start codon of $\mathrm{TcpH}$ is within tcpP. The position of the extra $G$ in strain KTT42, within a string of nine $G$ residues in wild-type DNA (bp 2393-2401), is noted by a triangle above the sequence. The site of the fusion of TnphoA to $t c p H$ in strain CS7-1 is noted by a triangle above the sequence between bp 2680 and 2681 . The position of the $\mathrm{T}$ missing in both $\mathrm{O} 395$ and KTT42 from the published sequence, resulting in a different deduced carboxy terminus of $\mathrm{TcpH}$, is noted by a triangle between bp 2755 and 2756. 
Table 3. Expression of cholera toxin and alkaline phosphatase activity in various strains following growth in ToxR-inducing or ToxRrepressing conditions.

\begin{tabular}{llllll}
\hline & \multicolumn{2}{c}{ Cholera toxin $^{\mathrm{a}}$} & & \multicolumn{2}{c}{ Alkaline phosphatase activity } \\
\cline { 2 - 3 } Strain & $\begin{array}{l}\text { ToxR-inducing } \\
\text { conditions }\end{array}$ & $\begin{array}{l}\text { ToxR-repressing } \\
\text { conditions }\end{array}$ & & $\begin{array}{l}\text { ToxR-inducing } \\
\text { conditions }\end{array}$ & $\begin{array}{l}\text { ToxR-repressing } \\
\text { conditions }\end{array}$ \\
\hline O395 & 5252 & $<1$ & $<1$ & $<1$ \\
CS7-1 & 106 & $<1$ & 207 & 15 \\
CS7-1 toxR & 10 & $<1$ & 183 & 24 \\
CS7-1 (white no. 1) & ND & ND & & $<1$ & $<1$ \\
CS7-1 (white no. 2) & ND & ND & 32 & 4
\end{tabular}

a. $\mathrm{ng} \mathrm{ml}^{-1} / \mathrm{OD}_{600}$ of culture.

b. Miller units per $\mathrm{OD}_{600}$ of culture.

ND, not done. amino terminus of $\mathrm{TcpH}$ and PhoA. We grew this strain overnight in ToxR-inducing conditions, plated on XPcontaining media, and recovered two white colonies out of approximately 10000 screened. Strain CS7-1 (white no. 1) had no measurable alkaline phosphatase activity (Table 3) and no TcpH::PhoA fusion protein detectable in whole cells by Western blot with anti-PhoA antisera (not shown); these are the findings expected for a mutation in $t c p H$, which shifts the reading frame upstream of the junction with TnphoA. Sequence upstream of the TnphoA fusion joint in CS7-1 (white no. 1) showed eight in place of the nine $\mathrm{G}$ residues in the string in $t c p H$ shown in Fig. 6; the remainder of the upstream sequences were normal. These results suggested that slipped-strand mutations in the $\mathrm{G}$ string within $t c p H$ arise at a frequency of approximately 1 in $10^{-4}$ after overnight growth. Strain CS7-1 (white no. 2) had reduced but regulated alkaline phosphatase activity (Table 3 ), reduced but present $\mathrm{TcpH}:$ :PhoA fusion protein by Western blot (not shown) and normal sequence upstream of the $t c p H$ fusion joint with TnphoA, consistent with a mutation further upstream in the tcp $P H$ promoter. We screened for reversion of strain CS7-1 (white no. 1) back to a blue colony phenotype after overnight growth in the same conditions, but did not detect revertants in approximately $10^{4}$ colonies screened.

Frameshift mutations in $\mathrm{tcpH}$ accumulate in the majority of colonies over several days of growth in ToxRinducing conditions

Serial passage of strain CS7-1 in ToxR-inducing conditions produced a majority of white colonies by 5 days of culture. In contrast, few or no white colonies were seen after serial passage in ToxR-repressing conditions or in minimal media (Table 4). Expression of TcpH::PhoA under ToxRinducing conditions may slow growth relative to mutants of CS7-1 that no longer express this potentially toxic fusion protein. This may provide a growth advantage for such mutants, potentially overestimating their frequency. Accordingly, we passaged wild-type strain 0395 in ToxR-inducing conditions over 5 days, in parallel with CS7-1. By the fourth and fifth days of passage, we no longer observed autoagglutination of the cultures. Of 40 individual colonies tested on day 5,38 failed to autoagglutinate following overnight growth in ToxR-inducing conditions, and all nine of a sample of these colonies also had substantial reductions in cholera toxin expression $\left(<1-101 \mathrm{ng} \mathrm{m}^{-1} /\right.$ $\left.\mathrm{OD}_{600}\right)$; the two colonies that still produced autoagglutination also continued to produce wild-type levels of cholera toxin (>3000 $\mathrm{ng} \mathrm{ml}^{-1} / \mathrm{OD}_{600}$ ). Sequence of PCR-amplified $t c p H$ genes revealed that seven of nine colonies that failed to autoagglutinate had slipped-strand mutations in $t c p H$ (10 $\mathrm{G}$ residues in place of nine), while one of the colonies that retained the wild-type phenotypes also retained nine $\mathrm{G}$ residues in the polyguanine tract in $t c p H$. We conclude that slipped-strand mutations in $t c p H$ accumulate in the majority of colonies after 5 days of serial passage in ToxR-inducing conditions.

\section{Discussion}

Expression of the ToxR regulon is strongly influenced by
Table 4. Serial passage of strain CS7-1 over 5 days in different growth conditions ${ }^{a}$.
Number of white colonies/Approximate number of colonies screened

\begin{tabular}{lrrrrr}
\cline { 2 - 5 } Growth condition & Day 1 & Day 2 & Day 3 & Day 4 & Day 5 \\
\hline ToxR-inducing conditions & $0 / 3500$ & $6 / 6500$ & $60 / 8000$ & $1000^{\mathrm{b}} / 4000$ & $4500^{\mathrm{b}} / 6000$ \\
ToxR-repressing conditions & $0 / 1500$ & $0 / 3000$ & $0 / 3500$ & $0 / 2500$ & $0 / 3000$ \\
Minimal media & $0 / 6000$ & $0 / 4000$ & $0 / 6000$ & $2 / 3500$ & $4 / 4000$ \\
\hline
\end{tabular}

a. After each overnight incubation, the cultures were back-diluted 1:1000 and grown again to stationary phase.

b. Approximate number. 
environmental conditions; evidence suggests that this regulation occurs at the level of tox $T$ transcription (DiRita et al., 1991; Higgins et al., 1992). The data presented here suggest that $\mathrm{TcpH}$ is required in addition to ToxR for maximal transcription of toxT. Activation of transcription of toxT could either reflect enhanced transcription at the ToxRdependent promoter of tox $T$ itself or enhanced transcription at the $t c p A$ promoter, with subsequent readthrough transcription of toxT. Either of these possibilities are consistent with the original suggestions of Taylor et al. (1988) and Shaw et al. (1990) that TcpH is a positive regulator of the $t c p A$ operon.

$\mathrm{TcpH}$ shows no significant homology to proteins in the database (Ogierman et al., 1996), providing few clues as to how $\mathrm{TcpH}$ might affect toxT transcription. Cell localization studies for $\mathrm{TcpH}$ are not yet available; however, there is a hydrophobic stretch of amino acids at positions 7-27, which could either function as a signal sequence or as an anchor for the protein in the inner membrane. The alkaline phosphatase activity of the $\mathrm{TcpH}::$ PhoA fusion in strain CS7-1 is consistent with the carboxy terminus of this protein being localized in the periplasm. If this topology is correct, it would suggest that little, if any, of TcpH is located within the cytoplasm, making a direct role for this protein in transcriptional activation less likely. This location, however, may allow $\mathrm{TcpH}$ to transduce environmental signals, such as temperature and/or $\mathrm{pH}$, to an additional regulatory protein that can then activate transcription. The carboxy terminus of Tox $R$ is located in the periplasm, and one possibility is that the periplasmic domains of $\mathrm{TcpH}$ and ToxR interact directly. Another possibility is that $\mathrm{TcpH}$ interacts with another protein, which in turn interacts with ToxR or activates transcription of toxT.

Transcription of the $t c p P H$ operon is regulated by $\mathrm{pH}$ and/or temperature, independently of ToxR or ToxT; much of the $\mathrm{pH}$ and temperature dependence of the ToxR regulon may occur via this regulated expression of tcpPH. A tcpH mutant strain, however, still demonstrates residual environmentally regulated expression of cholera toxin and $\mathrm{TcpA}$, suggesting that some regulation in response to $\mathrm{pH}$ and/or temperature occurs by another mechanism.

Champion et al. (1997) have postulated that the ToxR regulon consists of both ToxT-independent and ToxTdependent branches. Expression of OmpU is ToxT independent, and this expression is regulated by temperature, but much less so by $\mathrm{pH}$. Expression of the ToxT-dependent branch of the Tox $\mathrm{R}$ regulon, including expression of TcpA and cholera toxin, is regulated by both $\mathrm{pH}$ and temperature. Since a $t c p H$ mutant produced a normal amount of OmpU in response to environmental signals (i.e. the mutation did not affect the ToxT-independent branch), at least two possibilities can be considered: (i) $\mathrm{TcpH}$ affects expression of the ToxR regulon only in the
ToxT-dependent branch, acting at the level of toxT or tcpA transcription without affecting ToxR function; or (ii) $\mathrm{TcpH}$ activates ToxR function, but transcription of toxT or tcpA is more sensitive to modulation of ToxR function by environmental signals than is transcription of ompU. The difference between temperature and $\mathrm{pH}$ regulation of the two branches of the Tox $\mathrm{R}$ regulon could reflect a direct effect of $\mathrm{pH}$ on toxT or tcpA transcription, independently of ToxR. Indeed, Skorupski and Taylor (1997) have recently shown that cAMP-CRP in $V$. cholerae represses expression of both cholera toxin and TcpA in response to the non-permissive $\mathrm{pH}$ and that this repression is independent of ToxR. They identified a putative CAMP-CRP-binding site overlapping the -35 sequence of the promoter of $\operatorname{tcp} A$, suggesting that cAMP-CRP may repress transcription of $\operatorname{tcp} A$, with reduced readthrough transcription of tox $T$ and, therefore, reduced expression of cholera toxin, but without an effect on the expression of OmpU. A model for the regulation of virulence gene expression in V. cholerae is presented in Fig. 7.

There are interesting parallels between the expression of Tcp and the Myf surface antigen in Yersinia enterocolitica, a fibrillar structure that is homologous to the $\mathrm{pH} 6$ antigen of $Y$. pestis. Transcription of $m y f A$, which encodes the $21 \mathrm{kDa}$ major subunit of this antigen, is regulated in $Y$. enterocolitica by temperature and $\mathrm{pH}$. Transcription of $m y f A$ requires the products of two upstream genes, myfE and $m y f F$. The reading frame of myfE overlaps with the start codon of myfF. MyfF has a hydrophobic region at the amino terminus, and cell localization studies suggest that it is associated with the inner membrane through this hydrophobic domain, with the carboxy terminus in the periplasm (Iriarte and Cornelis, 1995). The organization of these two genes in $Y$. enterocolitica is very similar to that of $t c p P$ and $t c p H$ in $V$. cholerae. Also, the temperature- and $\mathrm{pH}$-regulated expression of $m y f A$ is similar to $\operatorname{tcp} A$, and the cellular localization of MyfF may resemble $\mathrm{TcpH}$. However, we did not find any significant amino acid homology between the MyfE and MyfF proteins, and $\mathrm{TcpP}$ and $\mathrm{TcpH}$ (not shown), suggesting that these systems are not highly related at the amino acid sequence level.

Phase variation in the expression of bacterial virulence genes has been reported previously, including a number of examples in which slipped-strand mutations within the open reading frames of genes are responsible. In Neisseria gonorrhoeae, phase variation of expression of outer membrane protein II occurs by a change in the number of CTCTT tandemly repeated sequences, producing a frameshift within the signal peptide of the gene encoding this protein; this provides a translational control mechanism for phase variation in the expression of individual outer membrane protein II alleles (Murphy et al., 1989). Different strains of $N$. gonorrhoeae also express a variety 


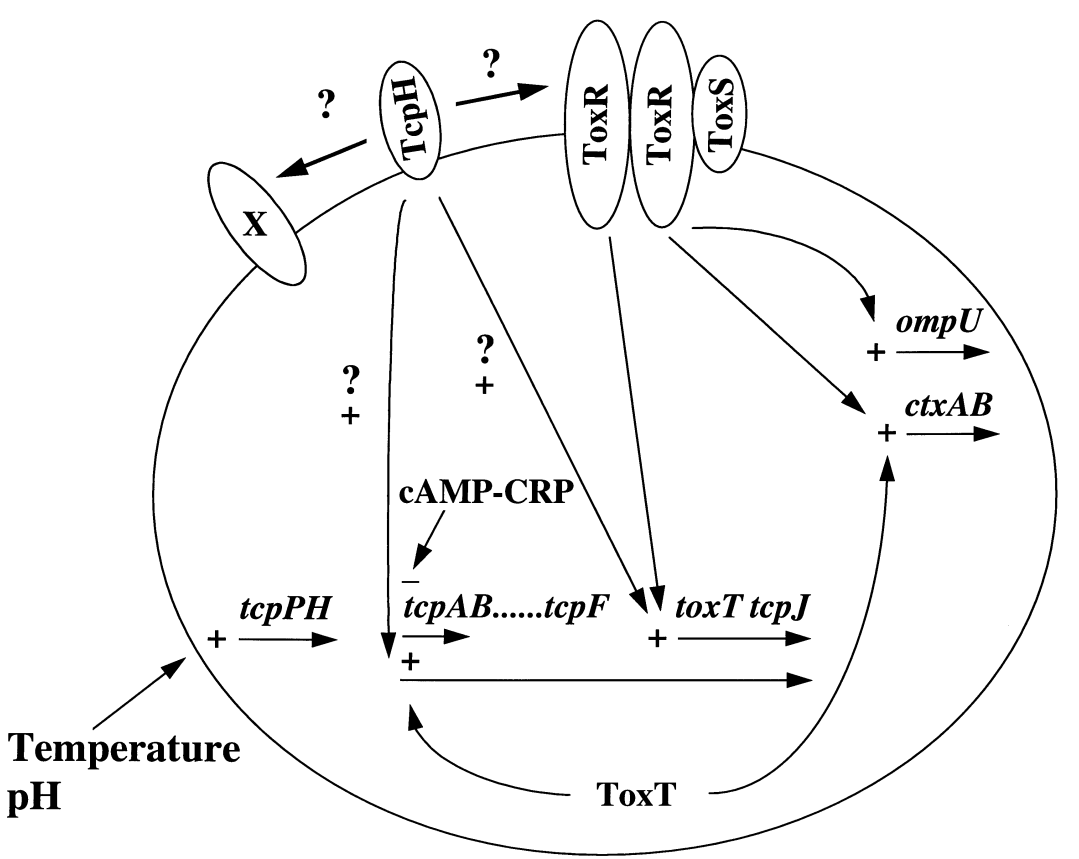

Fig. 7. Model for regulation of the ToxR regulon in $V$. cholerae, incorporating previous observations as well as those in the present study (see text for discussion). TcpH might either activate ToxR or another hypothetical protein $(\mathrm{X})$ to couple environmental signals to activation of transcription at either the toxT or tcpA promoters (shown here as two possible sites of action). + denotes transcriptional activation, - denotes repression. of related lipo-oligosaccharide structures on their cell surface, and phase variation in lipo-oligosaccharide types relates to changes in the number of guanine residues in polyguanine tracts within individual open reading frames involved in the synthesis of different lipo-oligosaccharide structures (Yang and Gotschlich, 1996; Burch et al., 1997). In N. meningitidis, unencapsulated variants arise by deletion of one $C$ residue within a string of seven $C$ residues in the open reading frame of siaD, which encodes an enzyme involved in the synthesis of the polysialic acid capsule of this organism (Hammerschmidt et al., 1996). Similar deletions are found in unencapsulated isolates from infected patients, suggesting that phase variation of capsule expression in $N$. meningitidis occurs in vivo by slipped-strand mutation. In Bordetella pertussis, expression of several virulence genes is co-ordinately regulated by BvgA and BvgS in response to environmental signals, in a similar manner to the co-ordinate regulation of virulence gene expression in $V$. cholerae. Phase variation in the expression of virulence genes in $B$. pertussis occurs by a frameshift mutation, the addition of a $C$ residue in a string of six $C$ residues within the open reading frame of bvgS (Stibitz et al., 1989). The frequency of phase variation of bvgS in $B$. pertussis, $10^{-3}-10^{-6}$, is very similar to the frequency of $10^{-4}$ that we have observed here for tcpH.

Our results suggest that slipped-strand mutations in a polyguanine tract within $t c p H$ produce mutants of $V$. cholerae with reduced transcription of tox $T$ in response to environmental signals. When $V$. cholerae is grown serially in ToxR-inducing conditions, slipped-strand mutations in $t c p H$ accumulate in the culture, suggesting that such mutants, which do not express multiple cholera virulence factors, have a growth advantage in these conditions over wild type. We do not yet know whether such mutations occur during in vivo infection. However, one hypothesis would be that frameshift mutations in $t c p H$ arise during the course of human infection with $V$. cholerae, leading to the excretion of organisms into the environment that have enhanced growth potential when virulence factors needed for human infection are no longer required. If this hypothesis is correct, then reversion of the frameshift mutation to produce active $\mathrm{TcpH}$ by phase variation may occur when these organisms again enter the human gastrointestinal tract. We were not able to obtain such revertants during in vitro growth conditions, but these conditions may not appropriately mimic the gastrointestinal milieu first encountered by infecting $V$. cholerae.

Additional experiments are under way to examine the mechanism by which $\mathrm{TcpH}$ activates toxT transcription, potential interactions between $\mathrm{TcpH}$ and ToxR or other membrane proteins in $V$. cholerae, the mechanisms by which temperature and/or $\mathrm{pH}$ regulate transcription of $t c p P H$ and potential signals for the reversion of frameshift mutations in $t c p H$ that may occur during human infection.

\section{Experimental procedures}

\section{Bacterial strains, plasmids and media}

Bacterial strains and plasmids used in this study are shown in Table 5. All strains were maintained at $-70^{\circ} \mathrm{C}$ in LuriaBertani (LB) medium containing $15 \%$ glycerol. LB medium contained $10 \mathrm{~g}$ of tryptone, $5 \mathrm{~g}$ of yeast extract and $5 \mathrm{~g}$ of $\mathrm{NaCl}$ per litre. LB medium with or without the addition of the 
Table 5. Strains and plasmids used in this study.

\begin{tabular}{|c|c|c|}
\hline Strain or plasmid & Relevant characteristics & Reference or source \\
\hline \multicolumn{3}{|l|}{ V. cholerae } \\
\hline O395 & Classical strain; $\mathrm{Sm}^{r}$ & Lab collection \\
\hline O395-N1 & O395 $\Delta c t x A$ & Mekalanos et al. (1983) \\
\hline KTT42 & TnphoA derivative of $\mathrm{O} 395 ; \mathrm{Sm}^{\mathrm{r}} \mathrm{Km}^{\mathrm{r}}$ & This study \\
\hline KTT7-1 & KTT42, reverted to wild-type by marker exchange with pPAC7; $\mathrm{Sm}^{r}$ & This study \\
\hline JJM43 & O395-N1 $\Delta$ toxR; $\mathrm{Sm}^{\mathrm{r}}$ & Taylor et al. (1987) \\
\hline VJ675 & O395 $\Delta$ toxT $; \mathrm{Sm}^{r}$ & V.J. DiRita (unpublished) \\
\hline PAC29 & $\begin{array}{l}\text { KTT7-1, with the Xbal fragment of pPAC21, containing tcpl-C, tcpA::TnphoA, recombined } \\
\text { within the lacZ locus; } \mathrm{Sm}^{r} \mathrm{Km}^{r}\end{array}$ & This study \\
\hline CS7-1 & O395 tcpH::TnphoA; $\mathrm{Sm}^{r} \mathrm{Km}^{r}$ & Shaw et al. (1990) \\
\hline CS7-1 toxR & CS7-1 with mutation in toxR created by integration of suicide plasmid pVM55; $\mathrm{Sm}^{r} \mathrm{Km}^{r} \mathrm{Ap}^{r}$ & This study \\
\hline \multicolumn{3}{|l|}{ E. coli } \\
\hline $\mathrm{DH} 5 \alpha$ & $\begin{array}{l}\mathrm{F}^{-} \text {endA1 hsdR17 supE44 thi-1 recA1 gyrA96 relA1 } \Delta(\operatorname{argF-lacZYA}) \cup 169(\phi 80 d \text { lacZ } \\
\Delta M 15)\end{array}$ & Hanahan (1983) \\
\hline SM10入pir & thi thr leu tonA lacY supE recA::RP4-2-Tc::Mu $\lambda$ pir R6K & Miller and Mekalanos (1988) \\
\hline \multicolumn{3}{|l|}{ Plasmids } \\
\hline pVJ21 & pACYC184 with $3.6 \mathrm{kbp} \mathrm{BamHI}$ fragment containing toxR and toxS; $\mathrm{Cm}^{r}$ & Miller et al. (1989) \\
\hline pLAFR3 & Cloning vector; $\mathrm{Tc}^{\mathrm{r}} \mathrm{r}-\mathrm{m}$ & Staskawicz et al. (1987) \\
\hline pKTT5 & pLAFR3 with $3.6 \mathrm{kbp} \mathrm{BamHI}$ fragment from pVJ21, containing toxR and toxS; $\mathrm{Tc}^{r}$ & This study \\
\hline pMT5 & pMMB66HE with toxT PCR product under Ptac control; $\mathrm{Ap}^{\mathrm{r}}$ & DiRita et al. (1996) \\
\hline pKTT42 & pUC19 with $6250 \mathrm{bp} \mathrm{BamHI} \mathrm{TnphoA} \mathrm{fusion} \mathrm{fragment} \mathrm{from} \mathrm{KTT42;} \mathrm{Ap}^{r} \mathrm{Km}^{r}$ & This study \\
\hline pPAC7 & pGEM-11Zf(+) with $12 \mathrm{kbp}$ Xhol fragment from O395 $\lambda$ bacteriophage library; $\mathrm{Ap}^{r}$ & This study \\
\hline pPAC11 & $\begin{array}{l}\text { pUC19 with } 1.1 \mathrm{kbp} \text { toxT PCR product from } \mathrm{O} 395 \text { cloned into Bam HI and Sall sites for } \\
\text { sequencing; } \mathrm{Ap}^{\mathrm{r}}\end{array}$ & This study \\
\hline pPAC12 & pLAFR3 with $1.1 \mathrm{kbp}$ BamHI-HindIII fragment from pPAC11; $\mathrm{Tc}^{r}$ & This study \\
\hline pPAC13 & $\begin{array}{l}\text { pUC19 with } 1.1 \mathrm{kbp} \text { toxT PCR product from KTT42 cloned into BamHI and Sall sites for } \\
\text { sequencing; } A p^{r}\end{array}$ & This study \\
\hline pPAC15 & pLAFR3 with $1.1 \mathrm{kbp} \mathrm{BamHI-Hindlll}$ fragment from pPAC13; $\mathrm{Tc}^{r}$ & This study \\
\hline pCS2-1 & $\begin{array}{l}\text { pJM22.1 with a } 12.7 \mathrm{kbp} \mathrm{Xbal} \mathrm{fragment} \mathrm{of} \mathrm{the} t c p \text { operon, containing tcpl-C, } t c p A:: T n p h o A \text {; } \\
\mathrm{Ap}^{r} \mathrm{Km}^{r}\end{array}$ & Shaw et al. (1990) \\
\hline p6891MCS & $\begin{array}{l}\text { pBR322 containing an } 8 \mathrm{kbp} \text { fragment of } V \text {. cholerae lacZ, interrupted by a multiple cloning } \\
\text { site inserted at } K p n I \text { within lacZ; } \mathrm{Ap}^{r}\end{array}$ & Butterton et al. (1995) \\
\hline pPAC21 & $\begin{array}{l}\text { Xbal fragment from pCS2-1, containing tcpl-C, tcpA::TnphoA, subcloned into p6891MCS; } \\
\mathrm{Ap}^{r} \mathrm{Km}^{r}\end{array}$ & This study \\
\hline pCS8C8 & $\begin{array}{l}\text { pHC79-based cosmid containing } V . \text { cholerae genomic DNA from strain O395, including } \\
\text { tcpl-C; Ap }\end{array}$ & Shaw and Taylor (1990) \\
\hline pPAC22 & $\begin{array}{l}\text { PCR product of } t c p P H \text { from } V \text {. cholerae O395, amplified with } B a m \mathrm{HI} \text { ends and cloned into } \\
\text { the BamHI site of pUC19 for sequencing; } \mathrm{Ap}^{r}\end{array}$ & This study \\
\hline pPAC25 & $\begin{array}{l}\text { BamHI fragment of pPAC22, containing tcpPH of } V \text {. cholerae O395, cloned in pLAFR3 in } \\
\text { opposite orientation to the lac } Z \text { promoter; } T c^{r}\end{array}$ & This study \\
\hline pPAC30 & $\begin{array}{l}\text { PCR product of } t c p P H \text { from } V \text {. cholerae KTT42, amplified with } B a m H I \text { ends and cloned into } \\
\text { the BamHI site of pUC19 for sequencing; } \mathrm{Ap}^{r}\end{array}$ & This study \\
\hline pPAC32 & $\begin{array}{l}\text { BamHI fragment of pPAC30, containing tcpPH of } V \text {. cholerae KTT42, cloned in pLAFR3 in } \\
\text { opposite orientation to the lacZ promoter; Tc }\end{array}$ & This study \\
\hline pVM55 & pJM703.1 with $630 \mathrm{bp}$ EcoRI-Hpal internal fragment of toxR; $\mathrm{Ap}^{\mathrm{r}}$ & Miller and Mekalanos (1988) \\
\hline
\end{tabular}

$\mathrm{Sm}^{r}$, streptomycin resistance; $\mathrm{Km}^{r}$, kanamycin resistance; $\mathrm{Tc}^{r}$, tetracycline resistance; $\mathrm{Ap}^{r}$, ampicillin resistance; $\mathrm{Cm}^{\mathrm{r}}$, chloramphenicol resistance.

iron chelator 2,2-dipyridyl (Sigma) at a final concentration of $0.2 \mathrm{mM}$ was used for growth in low- or high-iron conditions respectively. Ampicillin (25 or $100 \mu \mathrm{g} \mathrm{ml}^{-1}$ ), chloramphenicol $\left(25 \mu \mathrm{g} \mathrm{ml}^{-1}\right)$, kanamycin $\left(45 \mu \mathrm{g} \mathrm{ml}^{-1}\right)$, streptomycin $(100 \mu \mathrm{g}$ $\mathrm{ml}^{-1}$ ), tetracycline $\left(5\right.$ or $15 \mu \mathrm{g} \mathrm{ml}^{-1}$ ), IPTG (Fisher Scientific, $1 \mathrm{mM}$ ), Xgal (Fisher Scientific; $40 \mu \mathrm{g} \mathrm{ml}^{-1}$ ) or XP (Fisher Scientific; $40 \mu \mathrm{g} \mathrm{ml}^{-1}$ ) were added as appropriate.

Bacteria were grown in LB medium at $\mathrm{pH} 6.5$ and $30^{\circ} \mathrm{C}$ to induce ToxR-dependent gene expression and in LB medium at $\mathrm{pH} 8.4$ and $37^{\circ} \mathrm{C}$ to repress ToxR-dependent gene expression (Miller and Mekalanos, 1988). Overnight cultures grown under ToxR-inducing conditions with moderate aeration were examined for autoagglutination as described previously (Taylor et al., 1987). We used M9 minimal medium with
$0.2 \%$ glycerol as the carbon source for serial passage experiments (Miller, 1992).

\section{Assays}

Alkaline phosphatase activity was determined as described previously (Goldberg et al., 1990b). Cholera toxin was assayed using a GM-1 ELISA as described previously (Holmgren, 1973). Because of some day-to-day variability in absolute values obtained, results were always compared between assays run on the same day. Results presented are representative of at least three independent experiments. Haemagglutinin/protease activity was detected by a minor modification of 
a previously described single-diffusion technique in agar containing $1 \%$ skim milk as substrate (Honda et al., 1987).

\section{Animal studies}

Competition between $V$. cholerae strains was assessed as described previously (Goldberg et al., 1990b). Wild-type (O395) and mutant (KTT42) V. cholerae strains demonstrated equal plating efficiencies on LB agar. Competitive indices were corrected for the input ratio.

The $\mathrm{LD}_{50}$ assays were performed by oral inoculation of 4 - to 6-day-old CD-1 mice with various doses of viable bacteria grown in $\mathrm{LB}$ medium at $30^{\circ} \mathrm{C}$, pelleted, washed and resuspended in LB medium. Four mice were used per dose of bacteria. Survival was determined at $36 \mathrm{~h}$, and results were analysed as described previously (Goldberg et al., 1990b).

\section{Genetic methods}

Isolation of plasmid and bacterial chromosomal DNA, preparation of RNA, restriction enzyme digests, agarose gel electrophoresis, plaque blot hybridization, Southern hybridization of DNA separated by electrophoresis and Northern blot analysis were performed according to standard molecular biological techniques (Sambrook et al., 1989). DNA fragments used as probes were radiolabelled with $\left[\alpha-{ }^{32} \mathrm{P}\right]-\mathrm{dCTP}$ by using a random priming labelling kit (Prime-It II Random Primer Labelling Kit; Stratagene). For Northern hybridizations, fragment probes were as follows: for toxRS, the BamHI fragment from pVJ21; for toxT, an internal fragment generated by PCR (not shown); for tcpA and tcpPH, fragments generated by PCR (see below). GeneScreen Plus hybridization transfer membranes (DuPont Biotechnology Systems, NEN Research Products) were used according to the manufacturer's protocols for Southern and Northern hybridizations. DNA sequencing was performed with the Sequenase DNA Sequencing Kit (US Biochemicals). For Northern blot analysis, one set of samples was stained with ethidium bromide to confirm that equal amounts of RNA were loaded into each lane.

\section{PCR}

PCR was done with a DNA minicycler (M.J. Research). After an initial incubation at $94^{\circ} \mathrm{C}$ for $4 \mathrm{~min}$, we used 25 cycles of $94^{\circ} \mathrm{C}$ for $1 \mathrm{~min}, 50^{\circ} \mathrm{C}$ for $1 \mathrm{~min}$ and $72^{\circ} \mathrm{C}$ for 1 min per kbp of amplified product. Oligonucleotide primers for PCR were as follows: for toxT (i) 5'-ACT GTC GAC GCA AAG CAT ATT CAG AGA AC-3' and (ii) 5'-CGC GGA TCC ATA CAA TCG AAA ATA GGA TC-3'. These oligonucleotides span bases 1051-1070 and 2152-2133 respectively of the previously published sequence of $V$. cholerae toxT (Higgins et al., 1992) and incorporate Sall and $\mathrm{BamHI}$ restriction site extensions at the upstream and downstream ends of the PCR product respectively; primers for tcpA were (i) 5'-GAA CAC GAT AAG AAA ACC GGT CAA GAG GG-3' and (ii) 5'-TGC AAC GCC GAA TGG AGC AGT ACC TTT AC-3'. These primers span bp 3376-3404 and 3990-3962 of GenBank accession number X64098; primers for tcpPH were (i) $5^{\prime}$ AAA GGA TCC TAA TAG ATA TGG AAT AGG CAC-3' and (ii) 5'-AAA GGA TCC GTA AAG ATG AAG AGA TGA CTT$3^{\prime}$. These primers span bp 1485-1505 and 2870-2850 of
GenBank accession number X64098 and incorporate BamHI restriction sites at either end.

For PCR analysis of the $t c p H$ genes from individual bacterial colonies, we prepared chromosomal DNA template by scraping a colony into $200 \mu \mathrm{l}$ of distilled water, boiling for $5 \mathrm{~min}$ and pelleting debris at 14000 r.p.m. for $2 \mathrm{~min}$; we used $5 \mu \mathrm{l}$ of supernatant directly in a PCR reaction. Primers to amplify tcpH were (i) 5'-TTG ATG AAG CTG ACT GTA GTC AAA-3' (bp 2076-2099 of GenBank accession number $\mathrm{X64098)}$ and (ii) as above for $t c p P H$.

\section{Primer extension of toxT $m R N A$}

RNA was prepared from cells grown in ToxR-inducing conditions, and primer extension using $10 \mu \mathrm{g}$ of bacterial RNA was carried out using the same primer and reaction protocol as described previously (Higgins and DiRita, 1994), with the exception that RNasin was omitted from the reaction. Reverse transcriptase products were resolved on an $8 \%$ sequencing gel.

\section{Strain constructions}

The TnphoA insertion in KTT42 was replaced by wild-type DNA to create strain KTT7-1 as follows. pPAC7, described below, was electroporated into KTT42; the strain was grown in LB overnight without antibiotic selection, and dilutions were plated on LB agar containing XP and glucose. We sought colonies that were kanamycin and ampicillin susceptible and white, representing a double recombinational event between the plasmid and chromosome, in which the TnphoA-containing fragment on the chromosome was replaced with corresponding wild-type sequences carried by the plasmid. The double recombinational event in KTT7-1 was confirmed by Southern hybridization (not shown). Strain PAC29 was derived from KTT7-1 using marker exchange with plasmid pPAC21 in a manner analogous to that described previously (Butterton et al., 1995). Inactivation of $V$. cholerae tox $R$ in CS7-1 was carried out as described previously (Miller and Mekalanos, 1988).

To construct plasmid pKTT42, the chromosomal TnphoA insert in KTT42 was first mapped as described previously (Butterton et al., 1992), revealing a unique $\mathrm{BamHI}$ site approximately $1250 \mathrm{bp}$ upstream of the fusion joint. KTT42 chromosomal DNA was digested to completion with BamHI; the single BamHI site in TnphoA is located downstream of the kanamycin resistance marker and the end of phoA. Fragments $(6-8 \mathrm{kbp})$ were size fractionated by gel electrophoresis, purified by the freeze-squeeze technique (Tautz and Renz, 1983) and ligated into the unique BamHI site of pUC19. The construct was confirmed by restriction enzyme digestion and Southern hybridization (not shown) and named pKTT42. DNA sequence upstream of the fusion joint was determined by sequencing.

A $\lambda$ bacteriophage library of 0395 chromosomal DNA was screened by colony blot for clones hybridizing to an oligonucleotide sequence upstream of the TnphoA fusion joint in KTT42. Nine hybridizing bacteriophage clones were isolated, and the hybridizing $12 \mathrm{kbp}$ Xhol fragment from one of these phages was ligated into the $\mathrm{Xhol}$ site of the broad-host-range plasmid pGEM-11Z(f+) and named pPAC7. The correct 
construction was confirmed by restriction enzyme digestion and Southern hybridization (not shown).

\section{Protein analysis}

For cholera toxin ELISA assays of whole-cell extracts, bacteria were grown overnight in ToxR-inducing conditions, pelleted, washed in an equal amount of phosphate-buffered saline and lysed by passage through a French pressure cell at 4500 psi. Periplasmic proteins were prepared as described previously (Hovde et al., 1988).

Whole-cell proteins for electrophoresis were prepared as described previously (Hovde et al., 1988), following growth in ToxR-inducing and ToxR-repressing conditions. Proteins were separated on a SDS-12.5\% or $15 \%$ polyacrylamide gel and visualized with Coomassie blue (for OmpU and OmpT) or transferred to a NitroBind membrane (Micron Separations) with a semi-dry blotting apparatus (Hoefer Scientific Instruments) for Western blot. Immunoreactive proteins were visualized by sequential incubation with polyclonal rabbit anti-TcpA or anti-ToxR antibodies (a gift from John J. Mekalanos) or anti-PhoA antibodies (5 Prime $\rightarrow 3$ Prime), followed by goat anti-rabbit IgG-conjugated alkaline phosphatase (Sigma) and staining for alkaline phosphatase activity as described previously (Hovde et al., 1988).

\section{Acknowledgements}

This work was supported by a Public Health Service grant (Al34968) from the NIAID to S.B.C. K.T.T. was the recipient of a National Research Service Award from the NIAID. We wish to thank Ron Taylor, Ken Peterson and John Mekalanos for many helpful discussions, Ken Peterson for the $\lambda$ bacteriophage library of $V$. cholerae O395, Ron Taylor for strain CS7-1 and plasmids pCS2-1 and pCS8C8, and John Mekalanos and Matthew Waldor for antisera.

\section{References}

Brown, R.C., and Taylor, R.K. (1995) Organization of tcp, acf, and toxT genes within a ToxT-dependent operon. Mol Microbiol 16: 425-439.

Burch, C.L., Danaher, R.J., and Stein, D.C. (1997) Antigenic variation in Neisseria gonorrhoeae: Production of multiple lipooligosaccharides. J Bacteriol 179: 982-986.

Butterton, J.R., Stoebner, J.A., Payne, S.M., and Calderwood, S.B. (1992) Cloning, sequencing, and transcriptional regulation of $v i u A$, the gene encoding the ferric vibriobactin receptor of Vibrio cholerae. J Bacteriol 174: 3729-3738.

Butterton, J.R., Beattie, D.T., Gardel, C.L., Carroll, P.A., Hyman, T., Killeen, K.P., Mekalanos, J.J., and Calderwood, S.B. (1995) Heterologous antigen expression in Vibrio cholerae vector strains. Infect Immun 63: 2689-2696.

Champion, G.A., Neely, M.N., Brennan, M.A., and DiRita, V.J. (1997) A branch in the ToxR regulatory cascade of Vibrio cholerae revealed by characterization of toxT mutant strains. Mol Microbiol 23: 323-331.

DiRita, V.J. (1992) Co-ordinate expression of virulence genes by ToxR in Vibrio cholerae. Mol Microbiol 6: 451-458.
DiRita, V.J., and Mekalanos, J.J. (1991) Periplasmic interaction between two membrane regulatory proteins, ToxR and ToxS, results in signal transduction and transcriptional activation. Cell 64: 29-37.

DiRita, V.J., Parsot, C., Jander, G., and Mekalanos, J.J. (1991) Regulatory cascade controls virulence in Vibrio cholerae. Proc Natl Acad Sci USA 88: 5403-5407.

DiRita, V.J., Neely, M., Taylor, R.K., and Bruss, P.M. (1996) Differential expression of the ToxR regulon in classical and El Tor biotypes of Vibrio cholerae is due to biotype-specific control over toxT expression. Proc Natl Acad Sci USA 93: 7991-7995.

Goldberg, M.B., Boyko, S.A., and Calderwood, S.B. (1990a) Transcriptional regulation by iron of a Vibrio cholerae virulence gene and homology of the gene to Escherichia coli Fur system. J Bacteriol 172: 6863-6870.

Goldberg, M.B., DiRita, V.J., and Calderwood, S.B. (1990b) Identification of an iron-regulated virulence determinant in Vibrio cholerae, using TnphoA mutagenesis. Infect Immun 58: 55-60.

Goldberg, M.B., Boyko, S.A., and Calderwood, S.B. (1991) Positive transcriptional regulation of an iron-regulated virulence gene in Vibrio cholerae. Proc Natl Acad Sci USA 88: 1125-1129.

Hammerschmidt, S., Muller, A., Sillmann, H., Muhlenhoff, M., Borrow, R., Fox, A., van Putten, J., Zollinger, W.D., GerardySchahn, R., and Frosch, M. (1996) Capsule phase variation in Neisseria meningitidis serogroup B by slipped-strand mispairing in the polysialyltransferase gene $(\operatorname{sia} D)$ : correlation with bacterial invasion and the outbreak of meningococcal disease. Mol Microbiol 20: 1211-1220.

Hanahan, D. (1983) Studies of transformation of Escherichia coli with plasmids. $J$ Mol Biol 166: 557-580.

Herrington, D.A., Hall, R.H., Losonsky, G., Mekalanos, J.J., Taylor, R.K., and Levine, M.M. (1988) Toxin, toxin-regulated pili, and the tox $R$ regulon are essential for Vibrio cholerae pathogenesis in humans. J Exp Med 168: 1487-1492.

Higgins, D.E., and DiRita, V.J. (1994) Transcriptional control of toxT, a regulatory gene in the ToxR regulon of Vibrio cholerae. Mol Microbiol 14: 17-29.

Higgins, D.E., Nazareno, E., and DiRita, V.J. (1992) The virulence gene activator ToxT from Vibrio cholerae is a member of the AraC family of transcriptional activators. $J$ Bacteriol 174: 6974-6980.

Holmgren, J. (1973) Comparison of the tissue receptors for Vibrio cholerae and Escherichia coli enterotoxins by means of gangliosides and natural toxoid. Infect Immun 8: 851-859.

Honda, T., Booth, B.A., Boesman-Finkelstein, M., and Finkelstein, R.A. (1987) Comparative study of Vibrio cholerae non-O1 protease and soluble hemagglutinin with those of Vibrio cholerae O1. Infect Immun 55: 451-454.

Hovde, C.J., Calderwood, S.B., Mekalanos, J.J., and Collier, R.J. (1988) Evidence that glutamic acid 167 is an activesite residue of Shiga-like toxin I. Proc Natl Acad Sci USA 85: 2568-2572.

Iriarte, M., and Cornelis, G.R. (1995) MyfF, an element of the network regulating the synthesis of fibrillae in Yersinia enterocolitica. J Bacteriol 177: 738-744.

Kaufman, M., Shaw, C., Jones, I., and Taylor, R. (1993) 
Biogenesis and regulation of the Vibrio cholerae toxincoregulated pilus: analogies to other virulence factor secretory systems. Gene 126: 43-49.

Mekalanos, J.J., Swartz, D.J., Pearson, G.D.N., Harford, N., Groyne, F., and deWilde, M. (1983) Cholera toxin genes: nucleotide sequence, deletion analysis and vaccine development. Nature 306: 551-557.

Miller, J.H. (1992) A Short Course in Bacterial Genetics. Cold Spring Harbor, NY: Cold Spring Harbor Laboratory Press.

Miller, V.L., and Mekalanos, J.J. (1984) Synthesis of cholera toxin is positively regulated at the transcriptional level by ToxR. Proc Natl Acad Sci USA 81: 3471-3475.

Miller, V.L., and Mekalanos, J.J. (1988) A novel suicide vector and its use in construction of insertion mutations; osmoregulation of outer membrane proteins and virulence determinants in Vibrio cholerae requires toxR. J Bacteriol 170: 2575-2583.

Miller, V.L., Taylor, R.K., and Mekalanos, J.J. (1987) Cholera toxin transcriptional activator ToxR is a transmembrane DNA binding protein. Cell 48: 271-279.

Miller, V.L., DiRita, V.J., and Mekalanos, J.J. (1989) Identification of toxS, a regulatory gene whose product enhances tox $R$-mediated activation of the cholera toxin promoter. $J$ Bacteriol 171: 1288-1293.

Murphy, G.L., Connell, T.D., Barritt, D.S., Koomey, M., and Cannon, J.G. (1989) Phase variation of gonococcal protein II: regulation of gene expression by slipped-strand mispairing of a repetitive DNA sequence. Cell 56: 539-547.

Ogierman, M.A., and Manning, P.A. (1992) Homology of $\mathrm{TcpN}$, a putative regulatory protein of Vibrio cholerae, to the AraC family of transcriptional activators. Gene 116: 93-97.

Ogierman, M.A., Zabihi, S., Mourtzois, L., and Manning, P.A. (1993) Genetic organization and sequence of the promoterdistal region of the tcp gene cluster of Vibrio cholerae. Gene 126: 51-60.

Ogierman, M.A., Voss, E., Meaney, C., Faast, R., Attridge, S.R., and Manning, P.A. (1996) Comparison of the promoter proximal regions of the toxin-co-regulated tcp gene cluster in classical and El Tor strains of Vibrio cholerae 01. Gene 170: 9-16.
Sambrook, J., Fritsch, E.F., and Maniatis, T. (1989) Molecular Cloning: a Laboratory Manual. Cold Spring Harbor, NY: Cold Spring Harbor Laboratory Press.

Sandvist, M., Morales, V., and Bagdasarian, M. (1993) A protein required for secretion of cholera toxin through the outer membrane of Vibrio cholerae. Gene 123: 81-86.

Shaw, C.E., and Taylor, R.K. (1990) Vibrio cholerae O395 tcp $A$ pilin gene sequence and comparison of predicted protein structural features to those of type 4 pilins. Infect Immun 58: 3042-3049.

Shaw, C.E., Peterson, K.M., Mekalanos, J.J., and Taylor, R.K. (1990) Genetic studies of Vibrio cholerae TCP pilus biogenesis. In: Advances in Research on Cholera and Related Diarrheas. Sack, R.B., and Zinnaka, Y. (eds). Tokyo, Japan: KTK Scientific 7: 51-58.

Skorupski, K., and Taylor, R.K. (1997) Cyclic AMP and its receptor protein negatively regulate the coordinate expression of cholera toxin and toxin-coregulated pilus in Vibrio cholerae. Proc Natl Acad Sci USA 94: 265-270.

Staskawicz, B.D., Dahlbeck, D., Keen, N., and Napoli, C. (1987) Molecular characterization of cloned avirulence genes from race 0 and race 1 of Pseudomonas syringae pv. glycinea. J Bacteriol 169: 5789-5794.

Stibitz, S., Aaronson, W., Monack, D., and Falkow, S. (1989) Phase variation in Bordetella pertussis by frameshift mutation in a gene for a novel two-component system. Nature 338: 266-269.

Tautz, D., and Renz, M. (1983) An optimized freeze-squeeze method for recovery of DNA fragments. Anal Biochem 132: 14-19.

Taylor, R., Shaw, C., Peterson, K., Spears, P., and Mekalanos, J.J. (1988) Safe live Vibrio cholerae vaccines? Vaccine 6: 151-154.

Taylor, R.K., Miller, V.L., Furlong, D.B., and Mekalanos, J.J. (1987) Use of phoA gene fusions to identify a pilus colonization factor coordinately regulated with cholera toxin. Proc Natl Acad Sci USA 84: 2833-2837.

Yang, Q., and Gotschlich, E.C. (1996) Variation of gonococcal lipooligosaccharide structure is due to alterations in poly $\mathrm{G}$ tracts in lgt genes encoding glycosyl transferases. $J$ Exp Med 183: 323-327. 